\section{Intention Tremors}

Anna DePold Hohler ${ }^{1}$ and Marcus Ponce de Leon ${ }^{2}$ ${ }^{1}$ Boston University Medical Center, Boston, MA, USA

${ }^{2}$ William Beaumont Army Medical Center, El Paso, TX, USA

\section{Synonyms}

Action tremor; Volitional tremor

\section{Definition}

Intention tremor manifests as a marked increase in tremor amplitude during a terminal portion of targeted movement. Examples of intention tremor include cerebellar tremor and multiple sclerosis type tremor.

\section{Cross-References}

Tremor

\section{References and Readings}

Fahn, S., \& Jankovic, J. (2007). Tremors: Diagnosis and treatment. In Movement disorders (pp. 451-479). Philadelphia: Churchill Livingstone Elsevier. 